\title{
Effect of Exams Period on Prevalence of Myofascial Trigger Points in Neck in Secondary School Students
}

\author{
Dr. Syeda Mahanoor Zehra (PT) ${ }^{*}$, Dr. Muhammad Saad Khan (PT)
}

College of Physiotherapy, JPMC, Rafiqui، Sarwar Shaheed Rd, Karachi Cantonment, Karachi, Karachi City, Sindh 75510, Pakistan

DOI: $10.36348 /$ jaspe.2020.v03i01.001

| Received: 05.12.2019| Accepted: 12.12.2019 | Published: 11.01.2020

*Corresponding author: Dr. Syeda Mahanoor Zehra

Abstract

To evaluate the effect of exams period on prevalence of myofascial trigger points in the neck in secondary school students. 120 secondary school students with the age of 12-18 years were palpated for MTrP in the upper trapezius, Sternocledoimastoid and levetor scapulae muscles with ordinal ranking $(0=$ no finding, $1=$ tight band, $2=$ latent $\mathrm{MTrP}, 3=$ active MTrP). During the semester session and exam session. Pain intensity was measured on Numerical rating Scale scoring from 0 to 10. Participants showed higher prevalence of Myofascial Trigger Point in both Right and Left Upper Trapezius. Greater prevalence of MTrP in Right Sternocleidomastoid in comparison with Left Sternocleidomastoid. Levetor scapulae also showed greater prevalence on Right muscle than on the Left muscle. Students showed higher number of myofascial trigger point in the neck during exam session. It recommended that to minimize the formation of Myofascial Trigger point preventive measures should be taken in exam period.

Keywords: Myofascial Trigger point, upper trapezius, scalene, sternocleidomastoid, levetor scapulae, referred pain.

Copyright @ 2020: This is an open-access article distributed under the terms of the Creative Commons Attribution license which permits unrestricted use, distribution, and reproduction in any medium for non-commercial use (NonCommercial, or CC-BY-NC) provided the original author and source are credited.

\section{INTRODUCTION}

Myo means Muscle and Facial means connective tissue around muscle. Repetitive Strain and muscle injury leads to development of myofascial trigger point in a muscle like a contacted knot that produce pain and tightness in the muscle [1].

A hypersensitive reaction to mechanical stimulation that cause the increase in muscle irritability in a connective tissue. This hypersensitive reaction can cause local or regional referred pain is called trigger point [2].

Myofascial Trigger Point is donated, as "MTrP". Myofascial trigger point is frequently palpable thickened section, which is over excitable, sensitive and tender cord like band in a muscle fascia. Myofascial trigger points have different levels of sensitivity as Active MTrP, Latent MTrP and Satellite MTrPs.

Active myofacial trigger point eliciting as a spontaneous pain, referred pain and motor and autonomic symptoms on palpation to the trigger points muscle. This leads to a decrease in range of motion, muscle weakness and loss of coordination.
Latent myofascial trigger point causes pain over palpation or compression, a local twitch response and referred pain to associated areas [3]. Trigger point's significant feature is referred pain. It have a differentiation from the tender point. Central trigger point is always present at the center of the muscle belly, at the point where motor endplates enters the muscle. Multipennate muscles (example deltoid) may have its central plates in muscle belly. If muscles have its fibers in diagonal pattern, there may be various trigger points in it.

When a trigger point refers its pain to referred zone as a response to the central trigger point, trigger points may be formed, these trigger points are called "Secondary trigger Point". In this scenario, primary trigger point release me also resolve the problem with neighboring satellite trigger points. Examples: Paraspinal and/or abdominal muscles [4].

The diagnosis of myofascial trigger point is totally dependent on the subjective experience of the examiner or physician. Pressure algometry has been used to quantify the sensitivity of trigger points. A hand-held pressure meter with one $\mathrm{cm}^{2}$ rubber disc attached to a force gauge calibrated up to $10 \mathrm{~kg}$ is applied over a trigger point to measure its pain 
threshold. However, this method is not commonly employed clinically, and there have not been any imaging criteria for the diagnosis of trigger point [5].
Tigger points are mostly confused with Tender points. Tender points are features of fibromyalgia, discrete area of tenderness over muscle, bone, tendon that cause pain and tenderness. They do not refer pain to surrounding areas [6].

Table-1: Difference between tender and trigger point

\begin{tabular}{|l|l|}
\hline \multicolumn{1}{|c|}{ Trigger Point } & \multicolumn{1}{c|}{ Tender Point } \\
\hline $\begin{array}{l}\text { Tenderness at the site } \\
\text { Taut band } \\
\text { Local twitch response } \\
\text { Jump sign }\end{array}$ & Tenderness at the site \\
\hline One or more & More than one \\
\hline Anywhere in skeletal muscle & Present at symmetrically located areas at specific location \\
\hline Produce specific referred pain pattern & No referred pain pattern, cause whole body to increase pain sensitivity [7]. \\
\hline
\end{tabular}

The causes for the development of the myofascial trigger point may be affected by many factors, such as direct trauma to muscle, acute and chronic overload, psychological distress via systemic inflammation, homeostatic imbalance, radiculopathy, infection and other health issues like cigarette smoking. When a small number of muscle fibers produce a local contraction in a lager muscle or a muscle bundle a trigger point formed within the muscle. Depolarization of the muscle fiber causes excessive release of acetylcholine, leads to the trigger point in the muscle fiber. Whenever there is an imbalance between biomechanical composition with increase in the concentrations of acetylcholine, noradrenaline and serotonin and a lower $\mathrm{pH}$, this continuous contractions of muscle sarcomeres compression of the local blood supply which restricting the energy needs of that region. Due this obstruction in the energy, supply of muscle causes interaction between substances and the nociceptive nerve transmission which in turn produce localized referred pain within the muscle fiber at the neuromuscular Junction [5]. These produces pain and weakness in the associated structures. These pain patterns in the muscle follow specific nerve pathways [8].Trigger point can refer pain by two mechanism, referred pain and local twitch response; can be elicited by mechanical stimulation through palpation or by needling. The trigger point is usually elicited by acute or chronic injury to a muscle, tendon, ligament, joint, disc or nerve. The pathophysiology of referred pain or local twitch response is related to integration in the spinal cord. There are multiple sensitivity loci of the trigger point in the muscle bundle. These sensitive loci of the trigger point are sensitive to the nociceptive (pain) nerve ending. On compression to these sensitive loci of the trigger point can elicit a local twitch response with is usually associated with referred pain pattern. These sensitive loci can be present anywhere in the skeletal muscle, but is usually associated with highest concentration near the endplate where a trigger point is frequently found [9]. The pathogenesis behind the development of myofascial trigger point lacks evidence but many researchers agreed that acute trauma or repeated movement may cause the elicitation of myofascial trigger point. Lack of exercise, prolonged faulty posture, sleep disturbances, vitamin deficiencies and joint problems may lead to development of myofascial trigger point [6]. Trigger point clinically represented as decrease in the range of motion with persistent regional pain. They are often located in those muscles, which are involved in the maintaince of the posture, such as; muscle of shoulder, neck, Pelvic girdle, namely upper trapezius, scalene, sternocleidomastoid, levetor scapulae and quadratus lumborum.It does not involve any dermatological or neurological distribution and its reoccurrence can occur. On physical examination, joint swelling and neurologic deficits are absent but some systemic symptoms can present [11].

Trigger point can be located by the referred pain pattern described by the patient .This pain pattern guide the clinician where to look for the trigger point or trigger points within the muscle. There is palpable bands within a muscle a cord like band of fibers are present. Spot tenderness is located by the help of this cord like band, but the overlying muscle or thick subcutaneous tissue makes it inaccessible. When the band become accessible to palpation very small and very tender spot can locate in the palpable band of the muscle fiber. When the tension of the muscle fiber increase, it increases the sensitivity of this tender spot. When pressure is applied to the spot of the taut band of the muscle fiber patient respond by moving physically or by spontaneous exclamation.

When the trigger point is pressed through digital compression or by needle penetration of an active locus produces pain at the patient complaining area, and the patient recognizes it as pain. Active trigger point is identified by this method. Transient contraction of the taut band of muscle fiber produces a local twitch response associated with Trigger Point; it can be evoked by remarked snapping palpation of the taut band at the trigger point or through needle insertion in the active locus in the trigger point [12]. Myofascial trigger point reported as tension headache, tinnitus (ringing in the ear), temporomandibular joint pain, eye symptoms and 
torticollis in head and neck region. Myofascial trigger point pain is often referred to upper limb and pain in shoulder, which may mimic visceral pain and resemble tendonitis and bursitis [13]. Posterior neck and upper back contain latent trigger point, which is the universal findings in many of the muscles. Levator scapula and upper portion of trapezius contain active trigger points. Upper portion of trapezius refer pain to neck, levator scapulae muscle pain is referred to angle of the jaw and shoulder and this type of pain is referred as lancinating, especially on active contraction of this muscle. As the upper trapezius and levator scapulae act synergistically with several other muscles in elevation and fixation of the scapula it is common for a single trigger point in this region to initiating a spread of satellite trigger points through adjacent muscles which are part of the same functional unit [14].

Active myofascial trigger point show a greater decrease in pain through manual therapy. Selfmyofascial release increase the range of motion through exercises and reduce pain in affected muscle. Selfmyofascial technique involve the release of trigger point by applying pressure through tennis ball or with your finger called as slow burn: once you have placed your tennis ball or finger over the trigger point, hold it there and apply pressure in the same direction as the restriction. $30 \mathrm{sec}$ may be taken by this procedure, but still you have to maintain the pressure until you have feeling of burning sensation showed that a chemical reaction is taking place in the muscle [15].

Ischemia (lack of blood supply) with irritation and congestion of surrounding tissue. Ischemic compression also known as "static pressure". The theme of ischemic compression is to intensely enhance the blockage of blood supply to that area, which assures the resurgence of blood flow again. This helps in removal of waste products, supply necessary oxygen and help the tissue to heal. Blow flow increase to the area is called "hyperemia".

In ischemic compression technique, directly upon trigger point to stretch the muscle to the level of discomfort. Pressing a thumb or finger to produce bearable pain ( 7 to 8 on the pain scale of 10 ), then maintain this pressure. If patient, tense the muscle during this treatment then the treatment become useless by protecting the trigger point from pressure.as the discomfort starts to relief, increase pressure by adding thumb of finger from the other hand. It takes up to 1 minute with as much as 20 or $30 \mathrm{~m}$ pounds of pressure. Apply cold or hot pack following this treatment with active range of motion exercises [16]. In occupational medicine literature, there is evidence that injuries are more common when greater load is subject due faulty posture and poor body mechanics during work. Occupational trauma occurs as a result of repetitive microtrauma and myofascial shortening. Correction of the faulty posture should be the part of treatment sessions. Komiyama et al, studied the combined effect of postural training and behavioral therapy in the treatment of myofascial oral pain and concluded that persons who receive the combined therapy of postural training and behavioral therapy were be able to gain free unassisted mouth opening earlier than those treated with behavioral therapy alone; however, the difference is clinically minor [17]. Sprays, sport creams and ointments are useful in treating Myofascial trigger Points through their analgesic property. Topical application of menthol, peppermint, eucalyptus oil, casaicin and other herbal preparations and also trigger point pain. Capsaicin applied topically degranulates and depletes the substance P store in nerve ending, thereby decreasing pain [18]. A trigger point injection is given for the pain management of the trigger point. Injections such as: lidocaine (xylocaine) or bupivacaine (Marcaine), a mixture of anesthetics, or a corticosteroid (cortisone medication) alone or mixed with Lidocaine [19]. Trigger point acupuncture is a more aggressive, direct manipulation of muscular tightness (knots) known as trigger points. It seeks to generate repeated, involuntary twitching from the suspect muscle or muscle group and usually leads to an immediate reduction of tightness as well as a reduction or elimination of the related problems.

Whether the trigger points are caused by new or old injuries, improper or over-training, incorrect posture or body mechanics, or just life, trigger point acupuncture returns the natural balance to your muscles. It is one of the safest ways to address physical problems and usually involves only some short-term muscular soreness caused by the involuntary twitching. The soreness is similar to post workout soreness.

This drug-free process involves using knowledge of probable muscular causes of your problem and hands-on touch to locate the unnatural tightness. Next, the acupuncturist inserts an ultra-thin, single-use acupuncture needle into the suspect muscle and gently probes looking to produce localized involuntary twitching. This reaction has the effect of fatiguing the tight muscle and producing an immediate reduction or elimination of the tightness [20].

\section{LITERATURE REVIEW}

Study was conducted on the effect of exam period on prevalence of myofascial trigger points and head posture in undergraduate students.39 physical therapy students participated in this study, they were photographed by lateral view for forward head, neck and shoulder muscles were palpated for presence of any myofascial trigger points (MTrPs) during exam period of their academic session and during semesters period of their academic session. Right trapezius and levator scapula muscles showed high prevalence of active myofascial trigger point and left sternocleidomastoid and levator scapula muscle show high prevalence of latent MTrps along with it high rate of prevalence of 
tenderness over suboccipital musculature. Thus, physical therapy students show high prevalence of myofascial trigger points in the neck during exams period [21].

An experimental study conducted on shortterm effect of MTrP massage on cardiac autonomic tone in healthy subjects.30 subjects were randomize to treatment \& control group by alternate allocation with age- and sex-matched groups. Self-evaluation of muscle tension and emotional state with 5-mins cardiac interbeat interval recording, systolic and diastolic BP were recorded pre and post intervention. Significant decrease in the HR $(\mathrm{p}<0.01)$, systolic BP $(\mathrm{p}=0.02)$ and diastolic BP $(p<0.01)$ were recorded following an MTrp massage. Increase in the HR variability of parasympathetic activity $(\mathrm{p}<0.01)$ was revealed. Muscle tension and emotional state both showed significant improvement $\quad(\mathrm{P}<0.01)$.increase in cardiac parasympathetic activity by MTrP massage therapy to head, neck and shoulder was showed and improve relaxation in healthy subjects [22].

A blinded study conducted to evaluate MTrPs, pain; disability and sleep quality in individuals with mechanical neck pain.27 participants were observed. MTrPs were bilaterally palpate in upper trapezius, splenius capitis, semispinalis capitis, sternocleidomastoid, levator scapulae and scalene muscle. Pain recorded on numerical pain rate scale (010); disability was checked with Neck Disability Index; and sleep quality with Pittsburgh Sleep Quality Index disability was greater in patients than controls $(\mathrm{p}<.001)$ Intensity of pain $(\mathrm{r} 0.589 ; \mathrm{P}=.021)$ show worsening and disability $(\mathrm{r}=0.552 ; \mathrm{P}=.033)$. Patients revealed a higher $(\mathrm{p}=.002)$ number of active MTrps (mean2+_2) \& same no. of latent MTrPs (1.6+_1.4) then controls (latent MTrPs 1.3+_1.4).no significant correlation was found between active MTrP and intensity of pain, disability or sleep quality. Mechanical neck pain is associated with referred pain evoked by active MTrP in neck and shoulder muscle [23].

A nonrandomized control trial was performed, end plate potential are common to mid-fiber MTrPs.10 subject were palpated in 11 muscles to compare the prevalence of MTrP in 3 forms of endplate potentials at 1 test site and 2 control site.Spot tenderness were recognized on muscle as active $\mathrm{MTrP}$, a local twitch response to snapping palpation, and the tender spot evoked pain on pressure. All the 11 muscles showed endplate noise at trigger point site, 4 muscles showed endplate out of trigger point $(\mathrm{p}+0.024$. $)$ and end plate zone were not found in taut band sites $(\mathrm{P}=0.000034)$. MTrP reveal endplate are more prevalent as compared to outside of trigger point but still within endplate zone. MTrP contain endplate but it is not only the characteristic of MTrP [24].
A repeated measured single-blinded RCT was conducted on antinociceptive effect of ultrasound on trigger point sensitivity.44 patients with trigger point in the trapezius were involved on outpatient injury rehab clinic. Ultrasound to trapezius with $5 \mathrm{~min}$ at therapeutic intensity and $5 \mathrm{~min}$ at low intensity was provided to patients. After Therapeutic exposure of ultrasound to pain threshold elevated by 44.4(14.2) percent (before ultrasound test $35.4(8.5) \mathrm{N}$, after ultrasound test 51.1(12.8) N). Low intensity exposure of ultrasound to pain threshold showed no significant difference (before ultrasound 36.1 (6.1) N, after ultrasound 36.6(4.8) N). Trigger point sensitivity can be reduced by using therapeutic ultrasound [25].

A study conducted on quantification of changes in myofascial trigger point sensitivity with the pressure algometer following passive stretch. Correlation between referred pain and sensitivity of the myofascial trigger point was study in the report. Referred pain intensity rated on visual analog scale and pressure algometer was recorded pre and post treatment of passive muscle stretching of myofascial trigger point. The result showed that 20 subjects with bilateral or unilateral myofascial trigger point in head and neck revealed decline in sensitivity of myofascial trigger point in response to passive stretch and the trigger point sensitivity and intensity of referred pain are interrelated [26].

A pilot study conducted on self-determination theory-based self-myofascial release program in older adults with MTrPs in neck and back. A 12-week selfdetermination theory (SDT) based Self-myofascial release (SMR) program conducted in which 4-week group-based education and practice (EP) phase and an 8-week home-based self-management(SM) phase. Post EP and post SM, pain intensity and sensitivity to pain were assessed at baseline.15 participants showed significant enhancement at the post SM phase compared with the baseline. Increase adherence during SM phase as compared to EP phase. 4 behavioral changes were seen 1)"awareness of the effectiveness" 2)"a sense of duty to perform exercise" 3)"obedience to expert instruction" 4)"lack of friendship". In the treatment of MTrPs, SDT-based program shows effectiveness with motivation to participate in older adult [27].

A study was performed on Biomechanical associated with pain and inflammation are elevated in sites near to and remote from active MTrPs. A needle insertion technique used to identify active/latent/no MTrPs and predetermined sampling of $\mathrm{pH}$, Bradykinin, Substance P, calcitonin, TNF (alpha),IL(1B,6,8), serotonin and norepinephrine, using immuno capillary electrophoresis and capillary electrochromatography of Upper trapezius and gastrocnemius muscle was performed of analyte concentrations. Active MTrP are high in upper trapezius $(\mathrm{p}<.002)$; $\mathrm{pH}$ was low $(\mathrm{p}<.03)$.Analyte concentrations were high in upper 
trapezius ( $\mathrm{pH}$ not different) than in gastrocnemius. Higher concentrations of all analytes present in active group the latent and normal groups $(\mathrm{p}<.05) ; \mathrm{pH}$ was low $(\mathrm{p}<.01)[28]$.

A blinded, controlled study was conducted on MTrps in subjects presenting with mechanical neck pain.20 patients with 20 controls were participated. TrPs were palpated.The mean number of TrPs in neck in patients was 4.3(SD:0.9).out of which 2.5(SD:1.3)were latent and 1.8(SD:0.8)were active Trps.TrPs also present on control subjects(mean:2;SD:0.8)with latent $\mathrm{TrPs}$, active TrPs $(<0.001)$ shows differences on number of TrPs between both study groups. Cervical muscles show significant differences in the distribution of $\operatorname{TrPs}(p<0.01)$ except levator scapulae. Mechanical neck pain is associated with active MTrPs in healthy subjects [29].

An RCT was performed on treatment MTrPs with ultrasound combined with massage and exercise. Pain at rest and on daily activity (VAS), analgesic usage, global preference and index of MTrP were evaluated.6 months based questionnaire study was performed on long-term effect for treatment and control groups. Groups were randomized.

(a)Ultrasound, massage and exercise (b) shamultrasound, massage and exercise (c) control group. A significant reduction in index were found between treatment group (A and B) and control group $(\mathrm{C})$, no difference between group A, B and C on VAS, analgesic usage. Ultrasound and sham ultrasound shows no difference thus it is concluded that No reduction in pain can occur with US, apparently Number and intensity of MTrPs are reduced by massage and exercise [30].

A pilot study performed to detect myofascial trigger points in children with tension-type headache effect of trigger point and specific physiotherapy on headache frequency, intensity, and duration in children with episodic or chronic tension-type headache. Total nine girls (mean age 13.1 years) participated and receive trigger point therapy for two weeks. Frequency of headache reduced by $67.7 \%$, intensity by $74.3 \%$ and duration by $77.3 \%$ results show that tension-type headache is associated with active trigger point in children and specific physiotherapy is recommended for children with tension-type headache [31].

A study was conducted on Referred pain from myofacial trigger points in head and neck-shoulder muscles reproduces head pain features in children with chronic tension type headache.50 children with CTTH compared with controls of 50 age and sex-matched. On palpation, active TrPs were present referring pain to reproduce headache. Children with CTTH showed greater number of trigger points from their controls $(\mathrm{p}<0.001)$.Children with CTTH show active TrPs $(p<0.001)$.A significant positive association was observed with active TrPs and headache duration $(\mathrm{Rs}=0.315 ; \mathrm{p}=0.026)$ :the high number of trigger point greater the duration of headache referred pain area show significant difference $(\mathrm{p}<0.001)$ : CTTH children show larger referred pain area $(\mathrm{p}<0.001)$, sub occipital TrPs show larger referred pain area then remaining TrPs $(\mathrm{p}<0.001)$.it was concluded that active TrPs elicited referred and local pain to head, neck and shoulder similar pain pattern as spontaneous CTTH in children [32].

An experimental study was conducted on the effect of Kinesio taping technique on trigger point of the piriformis muscle.51 patients of piriformis muscle with TrPs were participated; experimental $(\mathrm{N}=33)$, control $(\mathrm{N}=18)$. No main effects were observed by repeated measurement ANOVA but the interactions between group and time for each depend variable (pain and ROM) were significant. After application of kinesio tape for 3 days significant improvement in pain and hip IR were observed, on the other hand there is no significant change in dependent variable in the control group. Kineso taping is effective in reducing pain of TrPs [33].

An RCT was conducted on dry needling alters trigger points in the upper trapezius muscle and reduce pain in subjects with chronic myofascial pain.52 participants completed the study with a mean age of 35.8 years. Trigger point status change from active to latent or resolved in 41 subjects, with 11 subjects shows no change $(p<0.001)$. A significant decrease in pain score noted $(\mathrm{p}<0.001)$. Post treatment cervical rotational asymmetry with significant improvement is as: unilateral/bilateral MTrPs ( $\mathrm{p}=. \mathrm{oo1}$ and $\mathrm{p}=21$, respectively), in pain pressure threshold in subjects with unilateral/bilateral MTrPs. $\quad(\mathrm{P}=.006$ and $\mathrm{p}=.012$ respectively) SF-36mental health and physical functioning subscale scores show improvement $(\mathrm{p}=.019$ and $\mathrm{p}=.03$ ) respectively; Oswestry Disability index show decrease in score $(\mathrm{p}=.003)$. MTrP pain can be reduced by Dry Needling. Reduction in pain prove statistical and clinical significant changes in status of trigger point. Mood, function and level of disability is associated with reduction in pain [34].

A study was conducted on Neurophysiological and clinical effect of dry needling in patients with upper trapezius myofascial trigger point. 20 subjects receive deep dry needling session. Sympathetic skin response (SSR), pain intensity (PI), pressure pain threshold (PPT) show significant improvement after dry needling. The neuromuscular junction response (NMJR) decreased and returned to normal after dry needling. Pain in active upper trapezius MTrP improve with single session of dry needling [35].

A systematic Review was performed on Evidence for the use of Ischemic compression and dry needling in the management of Trigger Points of the 
Upper Trapezius in patients with neck pain. Ischemic compression show moderate evidence and dry needling show strong evidence in reduction of pain intensity of MTrP. Pain decreases with active range of motion exercises(ischemic compression) compared to no or placebo intervention (ischemic compression and dry needling). Moderate evidence of improvement in side bending with both ischemic compression and dry needling. This systematic review provide recommendation for ischemic compression and dry needling for upper trapezius neck pain [36].

RCT was conducted on Responsiveness of Myofascial Trigger Points to Single and Multiple Trigger Point Release Massages. massage group show increase in Pain pressure threshold on all four muscles $(\mathrm{p}<0.0001$ for suboccipital; $\mathrm{P}<0.004$ for upper trapezius). after treatment analysis showed 1) increase in PPT (all P value <0.05) 2) a cumulative and sustained increase in PPT over baseline (all P values <0.05), an additional immediate increase in PPT at the final massage treatment (all p values $<0.005$, except upper trapezius left, $\mathrm{p}=0.17$ ). PPT of MTrPs increase with single or multiple massage. Even after multiple massage MTrps pain pressure threshold have greater capacity to increase [37].

A study was conducted to compare the efficacy of transcutaneous electrical nerve stimulation and therapeutic Ultrasound in the treatment of myofascial trigger points. Participants of both TENS group and ultrasound Group showed significant statistical improvement in range of motion measured through numerical rating scale and goniometer $(\mathrm{p}<0.05)$. However, U/s showed greater improvement as compared to TENS group. Thus it is concluded that pain intensity and cervical range of motion significantly improved with ultrasound compared to TENS. Ultrasound proved more statistically significant and clinically effective in comparison to TENS [38].

A RCT conducted on trigger point dry needling versus strain-counterstrain technique for upper trapezius myofascial trigger point. A significant time effect for pain $(\mathrm{p}<0.001)$, elicited pain $(\mathrm{p}<0.001)$, PPT $(\mathrm{p}<0.01)$ and neck disability index $(\mathrm{p}=0.016)$. decrease in pain at rest as follows: DN $18.5 \mathrm{~mm}(95 \% \mathrm{CI} 4.3$ to $32.7 \mathrm{~mm}$ ); SCS28.3mm (95\%CI 12.4 to $44.1 \mathrm{~mm}$ ); sham SCS $21.9 \mathrm{~mm}(955 \mathrm{C} 3.5$ to $\$) .1 \mathrm{~mm})$. disability points were significantly decrease in SCS $(1.8,95 \%$ CI 1.6 to 9.4) but not in $\mathrm{DN}(1.4,95 \% \mathrm{CI}-4.9$ to 2.1$)$ or sham SCS $(1.8,95 \%$ CI-6.4 to 2.7$)$ groups. No outcome measure show difference in SCS, sham SCS, and DN group. Pain relief by DN after few sessions as compared to Sham SCS or SCS [39].

An RCT conducted to compare the short-term outcomes between trigger point dry needling and trigger point manual therapy for the management of chronic mechanical neck pain. Both TrP dry needling and TrP
Manual therapy showed the same outcomes in terms of pain, function, and cervical range of motion. Pain pressure threshold revealed significant time-by-group interaction(p,.001):Pain pressure threshold increase in patients who had TrP dry needling as compared to those who had $\operatorname{TrP}$ manual therapy (between group difference: post treatment, $59.0 \mathrm{kPa} ; 95 \% \mathrm{CI}$ : 40.0,69.2; 1-week follow-up,69.2kPa;95\% CI: 49.5,79.1; 2-week follow-up, $\quad 78.9 \mathrm{kPa} ; \quad 95 \% \quad \mathrm{CI}: 49.5,89.0)$.it was concluded that pain, disability and cervical range of motion share similar outcome measures in 2 session treatment. Those in the TrP DN group experienced greater improvement in PPT over cervical spine [40].

A systematic review was conducted on the effectiveness of trigger point dry needling for multiple body region. Nineteen RCT included in this systematic review comparing either baseline to controls, significant differences were present for pain(14 studies), range of motion(ROM)(five studies) and function and quality of life(six studies). Majority of all the studies reviewed in this trial show benefits of trigger point dry needling for Myofascial Trigger Point in multiple body areas. Further high-quality research is needed to standardize the treatment of myofascial trigger point in multiple regions [41].

A pilot study was conducted on compression at myofascial trigger point on chronic neck pain provide pain relief through the prefrontal cortex and autonomic nervous system. Compression to prefrontal cortex significantly reduce subject pain due to MTrP compared to non-MTrP compression. MTrP compression group show decrease in prefrontal hemodynamic activity compare to non-MTrP compression Group. It was concluded that prefrontal hemodynamic activity and pain correlates with changes in autonomic activity. Worse Chronic neck pain show association with sympathetic activity, which recommend that compression of MTrp alters the autonomic nervous system activity through prefrontal cortex by reduction in pain [42].

An RCT was conducted to evaluate the shortterm changes in neck pain, widespread pressure pain sensitivity and cervical ROM after Application of Trigger Point Dry needling in patients with Acute Mechanical Neck pain. Treatment group revealed a marked decrease in neck pain, increase in pressure pain threshold, and greater increase in cervical ROM compared to other group who did not receive treatment at both 10 mints and 1 week after the intervention $(\mathrm{p}<.01)$. Moderate effect size between groups after TrPDN session (standardized mean score differences greater than 0.56) and effect size increase at 1-week follow-up (standardized mean score differences greater than 1.34).This study concluded that neck pain intensity, widespread pressure pain sensitivity reduced and cervical ROM increase with single session of TrPDN with acute mechanical neck pain patients [43]. 
A study was conducted on myofascial trigger point therapy: laser and dry needling. Literature review support the use of laser therapy over dry needling technique. Laser therapy provides an improvement in microcirculation which may favor the supply of oxygen to the cells when they are in the state of hypoxia and help in cell metabolism through the removal of metabolic waste products, thus it breaks the cycle of pain and muscle spasm. Laser show greater choice over the dry needling due to the fear of needle insertion by patients and healthcare professionals lacking skills in dry needling technique [44].

A prospective controlled study was conducted on comparison of laser, dry needling, and placebo laser treatments in myofascial pain syndrome. 60 patients with trigger point in the upper trapezius were pated in three randomly assigned groups. Laser therapy group show significant decrease in pain at rest, at activity and increase in pain threshold. Nottingham Health Profile evidence the superiority of laser therapy treatment over other treatments. Due to its noninvasiveness, ease and short-term application, laser therapy show a useful modality in myofascial pain syndrome [45].

\section{OBJECTIVE OF THE STUDY}

The purpose of this study is to evaluate the development of MTrps in neck muscles during exams session and to assist the association between active or latent myofascial trigger points with exams periods.

\section{Significance of the Study}

The findings of this study will rebound physical therapist knowledge of the extensiveness of myofascial trigger point in neck musculature in secondary school students. The greater demand is needed for the postural guidance among school students to justify the absence of myofascial trigger point, mechanical neck pain and study related stress. Thus, schools that apply recommended approach derived from the result of this study will be able to train students in a better way.

\section{Rationale of the Study}

This study was conducted because there is increasing number of students in our society with mechanical neck pain, which develop due to their study load. This study was conducted to create knowledge about postural guidance during study. Curriculum burden is also a contributing factor to the mental stress among students, through this study administration of school get to know how to deal with this aspect.

\section{METHODS AND MATERIALS Research Design}

Repeated measured observational study to evaluate the effect of exam period on prevalence of myofascial trigger point in neck in secondary school students.

\section{Duration of Study}

The duration of study was six month after the approval of synopsis.

\section{Sample Size}

The sample size was 120 , secondary school students aged 12-18 years from 3 schools (Alie's secondary School, Shenaz Public School and St. Rita School).

\section{Sampling Techniques}

Sampling method used in this study was nonprobability convenient sampling.

\section{Inclusion Criteria}

Secondary school students of age group 12-18 years, male and female were included in the study.

\section{Exclusion Criteria}

Any student with mechanical neck pain and with any skeletal or muscular disorder e.g. scoliosis or kyphosis was excluded from this study.

\section{Instrument/Tool Used \\ Preserve Stress Scale}

Sheldon Cohen developed it. The Perceived Stress Scale (PSS) is the most widely used psychological instrument for measuring the perception of stress. It is a measure of the degree to which situations in one's life are appraised as stressful. Items were design to tap how unpredictable, uncontrollable, and overloaded respondents find their lives. The scale also includes a number of direct queries about current levels of experienced stress. The PSS was design for use in community samples with at least a junior high school education. The items are easy to understand, and the response alternatives are simple to grasp. Moreover, the questions are of a general nature and hence are relatively free of content specific to any subpopulation group. The questions in the PSS ask about feelings and thoughts during the last month. In each case, respondents asked how often they felt a certain way.

\section{Assessment of Myofascial Trigger Point}

A systematic review was conducted on reliability of physical examination for diagnosis of myofascial trigger point. None of the studies reported interrater reliability estimates the identification of trigger point in symptomatic participants. Very limited number of studies with poor quality report that physical examination could not be a good assessment for the reliability of diagnosis of trigger point [45.

\section{Numerical Rating Scale}

A study was conducted to assess the pruritus intensity: prospective study on validity and reliability of the Visual analogue scale, Numerical rating scale and Verbal rating scale. Statistical analysis showed high reliability and concurrent validity of Numerical rating scale [46] 


\section{Procedure}

The data collection procedure initiate after the approval of synopsis from institutional review committee. Basic demographic data were collected using self-administered questionnaire, which include age, sex, self-reported weight and height (to calculate BMI). Consent form was send to parents for participation in study. After the approval of students to participate in study observation of myofascial trigger point was taken by observer and researcher. The observation was taken twice, first during exam period and second during semester period of course or vice versa. About half of the sample $(\mathrm{N}=50)$ was evaluate first time during the exam and second time during the semester, another half $(\mathrm{N}=50)$ were evaluated in an opposite order. NRS will also use to evaluate the neck pain among students. Before each measurement, the subjects filled a widely used perceived stress scale. In perceived stress scale (PSS), the questions were concern about feelings and thoughts during last month .First part consists of name, age, gender and date. Second part was regarding the stress level in students.

\section{DATA ANALYSIS}

All statistical compilations was done by using software SPSS version 16.0(SPSS Inc. Released 2007. SPSS for Windows, Version 16.0. Chicago, SPSS Inc.). Statistical analysis of the data conducted at $95 \%$ confidence interval. P-Value $<0.05$ considered statistically significant.

Descriptive statistics were used to characterize the age, sex, gender, BMI and compare continuous variable of perceive stress scale (PSS).

The muscle palpation finding were ranked on ordinal scale (0- no MTrps, 1-light band, 2 latent MTrp and 3-active MTrps) these findings were compared (semester v/s exams) on Wilcoxon rank sum test.

\section{Ethical Approval}

Ethical review committee of JPMC, Karachi, gave ethical approval for this study.

\section{DISCUSSION}

The finding of this study showed greater prevalence of Myofascial trigger point during exam session in correlation with the study's hypothesis. In connection with this study, many other studies support the presence of myofascial trigger point in neck muscles due to the exam stress in students with the presence of suboccipital tenderness [1]. Researchers attempts to identify the development of myofascial trigger point due to the presence of visual and postural stressors, which leads to the results that higher stressor elicits the MTrP development in conjunction with higher postural stress. Results of the study also showed higher sensitivity of myofascial trigger point in Right Upper Trapezius compared to the left upper trapezius [2]. Romen et al., results showed that sustain attention and muscle tension contributed to the increament of mental load which were mostly reflected by the tension in arms and shoulder girdle compare to the tension of forearm with the lesser degree of muscle tension [3]. In Kwon J et al., study, MTrP are referred pain pattern identified with the characteristic of myofascial trigger point which is usually center of the muscle belly with the reference of pain to the area above elbow level [4]. Kim HA et $a l$, concluded that myofascial trigger point of upper trapezius should be considered with decrease strength of shoulder abductor with restricted scapular elevation [5]. Upper Trapezius pain with Myofascial Trigger point associated with serratus anterior strength, showed a variance of $68.7 \%$ in visual analog scale where myofascial trigger point is evaluated in food service workers [6]. Rasimul Hasamatin et al., compare the muscular pain, neck pain and mental stress to the increased frequency of individual with the neck pain, whose study results consistent with this study that mental load results in neck pain as reported by Numerical Rating Scale [7]. In Steven James Linton study, lifestyle, ergonomics and psychosocial workplace factor influence the neck and back pain which is also found in this study through NRS which shows that study load effect pain intensity [8] higher level of anxiety and stress triggered by exam period in both subjects: healthy and patient with temporomandibular pain, when exam period approaches the level of stress increases as the school students are under stress of good grades and about their abilities to cope with study load, during this period they are widely exposed to prolonged sitting, prolong use of the computer, mental concentration, reading papers and psychological stress which leads to mechanical neck pain sometimes associated with referred pain; these points are under consideration of this study that anxiety and stress leads to muscular pains [9].

\section{RESULTS}

In this study, 119 students from different schools(Alie's school, shenaz public school and St. Rita school) were participated with the mean age of 13.96 +/- 1.392 (max. 18-min.12 years). Table-2 and Figure-1.

Out of 119,50 were male participants, 69 were female participants, and one participant did not mention his /her gender Table-3 and Figure-2.

BMI evaluated on self-reported basis, mean BMI (kilograms/height 2): $20.31+/-5.25$ (max.34.41min.9.06) table-4 and Figure-3.

The Perceived stress scale scoring, lowest score: Five until highest score 30 . Mean score of PSS: 18.26+/- 4.27 Table-5 and Figure-4.

Answer to the first question of PSS, In the last month, how often have you been upset because of something that happened unexpectedly 43 of the respondents said they never upset, 31 said that almost 
never upset, 28 said fairly often and 4 said very often Table-6 and Figure-5.

Second question, in the last month, how often have you felt that you were unable to control the important things in your life; 46 said never, 16 said almost never, 40 said sometimes, 10 said fairly

To the third question, in the last month, how often have you felt nervous and stressed, 23 replied never, 23 replied almost never, 36 replied sometimes, 15 replied fairly often, 18 replied very often Table- 8 and Figure-7.

Fourth question, in the last month, how often have you felt confident about your abilities to handle your personal problems, 24 replied never, 26 replied almost never, 37 replied sometimes, 17 replied fairly often and 23 replied very often Table- 9 and Figure-8.

Fifth question, in the last month, how often have you felt that things were going your way.13 answered never, 21 answered almost never, 39 answered sometimes, 15 answered fairly often and 31 answered very often Table-10 and Figure-9.

Sixth question, in the last month, how often have you found that you could not cope with all the things that you had to do.33 answered never, 29 answered almost never, 34 answered sometimes, 11 answered fairly often, 11 answered very often Table-11 and Figure-10.

Seventh question, in the last month, how often have you been able to control irritations in your life. 10 said never, 27 said almost never, 34 said sometimes, 14 said fairly often, 33 said very often Table-12 and Figure-11.

Eighth question, in the last month, how often have you felt that you were on the top of the things. 15 said never, 16 said almost never, 40 said sometimes, 22 said fairly often, 24 said very often Table-13 and Figure-12.

Ninth question, in the last month, how often have you been angered because of the things that were outside of your control. 14 responded to never, 20 responded to almost never, 38 responded to sometimes, 31 responded to fairly often, 16 responded to very often Table-14 and Figure-13.

Last question, in the last month, how often have you felt difficulties were peeling up so high that you could not overcome them 40 responded to never, 16 responded to almost never, 41 responded to sometimes, 12 responded to fairly often and responded to very often. Table-15 and Figure-14.

For NRS, subject reported NRS stress level with $4.57+/-2.234$, with most of the subject showing moderate pain on it Table-16 and Figure-15.

Presence of the MTrP is significantly more prevalent during exams in all Muscles; right Trapezius $\operatorname{MTrP}(\mathrm{p}=0.000)$; left trapezius $\operatorname{MTrP}(\mathrm{p}=0.000)$; right SCM $(p=0.12)$, left SCM $(p=0.006)$; right levator scapulae $(\mathrm{p}=0.000)$; left levator scapulae $(0.000)$ which is less than the p-value (0.05) Table-17.

Table-2: Mean age of participants

\begin{tabular}{|l|l|l|l|l|l|}
\hline \multicolumn{6}{|c|}{ Descriptive Statistics } \\
\hline & $\mathrm{N}$ & Minimum & Maximum & Mean & Std. Deviation \\
\hline Age & 119 & 12 & 18 & 13.96 & 1.392 \\
\hline Valid N (list wise) & 119 & & & & \\
\hline
\end{tabular}

Table-3: Frequency of gender

\begin{tabular}{|l|l|l|l|l|l|}
\hline \multicolumn{6}{|c|}{ Gender } \\
\hline \multirow{3}{*}{ Valid } & & Frequency & Percent & Valid Percent & Cumulative Percent \\
\cline { 2 - 6 } & Male & 50 & 41.7 & 42.0 & 42.0 \\
\cline { 2 - 6 } & Female & 69 & 57.5 & 58.0 & 100.0 \\
\hline & Total & 119 & 99.2 & 100.0 & \\
\hline Missing & System & 1 & .8 & & \\
\hline Total & 120 & 100.0 & & \\
\hline
\end{tabular}

Table-4: Mean of body mass index (BMI)

\begin{tabular}{|l|l|l|}
\hline \multicolumn{3}{|c|}{ Statistics } \\
\hline \multicolumn{2}{|c|}{ Bodymassindex } \\
\hline \multirow{2}{*}{$\mathrm{N}$} & Valid & 119 \\
\cline { 2 - 3 } & Missing & 1 \\
\hline \multicolumn{2}{|l|}{ Mean } & 20.3129 \\
\hline Median & 19.6970 \\
\hline Mode & 17.86 \\
\hline Std. Deviation & 5.25955 \\
\hline Minimum & .48 \\
\hline \multicolumn{2}{|l|}{ Maximum } & 34.41 \\
\hline
\end{tabular}


Table-5: Mean of PSS Scores

\begin{tabular}{|c|c|c|}
\hline \multicolumn{3}{|c|}{ Statistics } \\
\hline \multicolumn{3}{|c|}{ SMEAN(sum_questionnaire) } \\
\hline \multirow[t]{2}{*}{$\mathrm{N}$} & Valid & 121 \\
\hline & Missing & 0 \\
\hline \multicolumn{2}{|c|}{ Mean } & 18.264 \\
\hline \multicolumn{2}{|c|}{ Median } & 18.264 \\
\hline \multicolumn{2}{|c|}{ Mode } & $16.0^{\mathrm{a}}$ \\
\hline \multicolumn{2}{|c|}{ Std. Deviation } & 4.2792 \\
\hline \multicolumn{2}{|c|}{ Minimum } & 5.0 \\
\hline \multicolumn{2}{|c|}{ Maximum } & 30.0 \\
\hline
\end{tabular}

Table-6: How much participant had been upset

\begin{tabular}{|c|c|c|c|c|c|}
\hline \multicolumn{6}{|c|}{ qno1 } \\
\hline & & Frequency & Percent & Valid Percent & Cumulative Percent \\
\hline \multirow[t]{6}{*}{ Valid } & NEVER & 43 & 35.8 & 36.1 & 36.1 \\
\hline & ALMOST NEVER & 31 & 25.8 & 26.1 & 62.2 \\
\hline & SOMETIMES & 28 & 23.3 & 23.5 & 85.7 \\
\hline & FAIRLY OFTEN & 13 & 10.8 & 10.9 & 96.6 \\
\hline & VERY OFTEN & 4 & 3.3 & 3.4 & 100.0 \\
\hline & Total & 119 & 99.2 & 100.0 & \\
\hline Missing & System & 1 & .8 & & \\
\hline Total & & 120 & 100.0 & & \\
\hline
\end{tabular}

Table-7: Participant feeling about control of their emotions

\begin{tabular}{|l|l|l|l|l|l|}
\hline \multicolumn{6}{|c|}{ qno2 } \\
\hline \multirow{3}{*}{ Valid } & & Frequency & Percent & Valid Percent & Cumulative Percent \\
\cline { 2 - 6 } & NEVER & 46 & 38.3 & 38.7 & 38.7 \\
\cline { 2 - 6 } & ALMOST NEVER & 16 & 13.3 & 13.4 & 52.1 \\
\cline { 2 - 6 } & SOMETIMES & 40 & 33.3 & 33.6 & 85.7 \\
\cline { 2 - 6 } & FAIRLY OFTEN & 10 & 8.3 & 8.4 & 94.1 \\
\cline { 2 - 6 } & VERY OFTEN & 7 & 5.8 & 5.9 & 100.0 \\
\cline { 2 - 6 } & Total & 119 & 99.2 & 100.0 & \\
\hline Missing & System & 1 & .8 & & \\
\hline Total & 120 & 100.0 & & \\
\hline
\end{tabular}

Table-8: Participant feeling about nervousness and stress

\begin{tabular}{|l|l|l|l|l|l|}
\hline \multicolumn{5}{|c|}{$\mathbf{q n o 3}$} \\
\hline \multirow{3}{*}{ Valid } & & Frequency & Percent & Valid Percent & Cumulative Percent \\
\cline { 2 - 6 } & NEVER & 23 & 19.2 & 20.0 & 20.0 \\
\cline { 2 - 6 } & ALMOST NEVER & 23 & 19.2 & 20.0 & 40.0 \\
\cline { 2 - 6 } & SOMETIMES & 36 & 30.0 & 31.3 & 71.3 \\
\cline { 2 - 6 } & FAIRLY OFTEN & 15 & 12.5 & 13.0 & 84.3 \\
\cline { 2 - 6 } & VERY OFTEN & 18 & 15.0 & 15.7 & 100.0 \\
\cline { 2 - 6 } & Total & 115 & 95.8 & 100.0 & \\
\hline Missing & System & 5 & 4.2 & & \\
\hline Total & 120 & 100.0 & & \\
\hline
\end{tabular}

Table-9: Participants feeling about their confidence

\begin{tabular}{|l|l|l|l|l|l|}
\hline \multicolumn{5}{|c|}{ QNO4_R } \\
\hline \multirow{3}{*}{ Valid } & & Frequency & Percent & Valid Percent & Cumulative Percent \\
\cline { 2 - 6 } & NEVER & 24 & 20.0 & 20.5 & 20.5 \\
\cline { 2 - 6 } & ALMOST NEVER & 16 & 13.3 & 13.7 & 34.2 \\
\cline { 2 - 6 } & SOMETIMES & 37 & 30.8 & 31.6 & 65.8 \\
\cline { 2 - 6 } & FAIRLY OFTEN & 17 & 14.2 & 14.5 & 80.3 \\
\cline { 2 - 6 } & VERY OFTEN & 23 & 19.2 & 19.7 & 100.0 \\
\cline { 2 - 6 } & Total & 117 & 97.5 & 100.0 & \\
\hline Missing & System & 3 & 2.5 & & \\
\hline Total & 120 & 100.0 & & \\
\hline
\end{tabular}


Table-10: Participants feeling about their plans

\begin{tabular}{|c|c|c|c|c|c|}
\hline \multicolumn{6}{|c|}{ ONO5 R } \\
\hline & & Frequency & Percent & Valid Percent & Cumulative Percent \\
\hline \multirow[t]{6}{*}{ Valid } & NEVER & 13 & 10.8 & 10.9 & 10.9 \\
\hline & ALMOST NEVER & 21 & 17.5 & 17.6 & 28.6 \\
\hline & SOMETIMES & 39 & 32.5 & 32.8 & 61.3 \\
\hline & FAIRLY OFTEN & 15 & 12.5 & 12.6 & 73.9 \\
\hline & VERY OFTEN & 31 & 25.8 & 26.1 & 100.0 \\
\hline & Total & 119 & 99.2 & 100.0 & \\
\hline Missing & System & 1 & .8 & & \\
\hline \multicolumn{2}{|l|}{ Total } & 120 & 100.0 & & \\
\hline
\end{tabular}

Table-11: Participant feeling about their coping ability

\begin{tabular}{|l|l|l|l|l|l|}
\hline \multicolumn{5}{|c|}{ qno6 } \\
\hline \multirow{3}{*}{ Valid } & NEVER & Frequency & Percent & Valid Percent & Cumulative Percent \\
\cline { 2 - 6 } & ALMOST NEVER & 29 & 27.5 & 28.0 & 28.0 \\
\cline { 2 - 6 } & SOMETIMES & 34 & 24.2 & 24.6 & 52.5 \\
\cline { 2 - 6 } & FAIRLY OFTEN & 11 & 28.3 & 28.8 & 81.4 \\
\cline { 2 - 6 } & VERY OFTEN & 11 & 9.2 & 9.3 & 90.7 \\
\cline { 2 - 6 } & Total & 118 & 98.3 & 9.3 & 100.0 \\
\hline Missing & System & 2 & 1.7 & & \\
\hline Total & 120 & 100.0 & & \\
\hline
\end{tabular}

Table-12: Participants feeling about their control of life

\begin{tabular}{|l|l|l|l|l|l|}
\hline \multicolumn{5}{|c|}{ QNO7_R } \\
\hline \multirow{3}{*}{ Valid } & NEVER & Frequency & Percent & Valid Percent & Cumulative Percent \\
\cline { 2 - 6 } & ALMOST NEVER & 27 & 8.3 & 8.5 & 8.5 \\
\cline { 2 - 6 } & SOMETIMES & 34 & 22.5 & 22.9 & 31.4 \\
\cline { 2 - 6 } & FAIRLY OFTEN & 14 & 28.3 & 28.8 & 60.2 \\
\cline { 2 - 6 } & VERY OFTEN & 33 & 27.5 & 28.0 & 72.0 \\
\cline { 2 - 6 } & Total & 118 & 98.3 & 100.0 & \\
\hline Missing & System & 2 & 1.7 & & \\
\hline Total & 120 & 100.0 & & \\
\hline
\end{tabular}

Table-13: Participant feeling about their confidence

\begin{tabular}{|l|l|l|l|l|l|}
\hline \multicolumn{5}{|c|}{ QNO8_R } \\
\hline \multirow{3}{*}{ Valid } & & Frequency & Percent & Valid Percent & Cumulative Percent \\
\cline { 2 - 6 } & NEVER & 15 & 12.5 & 12.8 & 12.8 \\
\cline { 2 - 6 } & ALMOST NEVER & 16 & 13.3 & 13.7 & 26.5 \\
\cline { 2 - 6 } & SOMETIMES & 40 & 33.3 & 34.2 & 60.7 \\
\cline { 2 - 6 } & FAIRLY OFTEN & 22 & 18.3 & 18.8 & 79.5 \\
\cline { 2 - 6 } & VERY OFTEN & 24 & 20.0 & 20.5 & 100.0 \\
\cline { 2 - 6 } & Total & 117 & 97.5 & 100.0 & \\
\hline Missing & System & 3 & 2.5 & & \\
\hline Total & 120 & 100.0 & & \\
\hline \multicolumn{2}{|l|}{} & & & \\
\hline
\end{tabular}

Table-14: Participants feeling about anger

\begin{tabular}{|l|l|l|l|l|l|}
\hline \multicolumn{5}{|c|}{ qno9 } \\
\hline \multirow{3}{*}{ Valid } & & Frequency & Percent & Valid Percent & Cumulative Percent \\
\cline { 2 - 6 } & NEVER & 14 & 11.7 & 11.8 & 11.8 \\
\cline { 2 - 6 } & ALMOST NEVER & 20 & 16.7 & 16.8 & 28.6 \\
\cline { 2 - 6 } & SOMETIMES & 38 & 31.7 & 31.9 & 60.5 \\
\cline { 2 - 6 } & FAIRLY OFTEN & 31 & 25.8 & 26.1 & 86.6 \\
\cline { 2 - 6 } & VERY OFTEN & 16 & 13.3 & 13.4 & 100.0 \\
\cline { 2 - 6 } & Total & 119 & 99.2 & 100.0 & \\
\hline Missing & System & 1 & .8 & & \\
\hline Total & 120 & 100.0 & & \\
\hline
\end{tabular}


Table-15: Participants feeling about their difficulties

\begin{tabular}{|c|c|c|c|c|c|}
\hline \multicolumn{6}{|c|}{ qno10 } \\
\hline & & Frequency & Percent & Valid Percent & Cumulative Percent \\
\hline \multirow[t]{6}{*}{ Valid } & NEVER & 40 & 33.3 & 33.6 & 33.6 \\
\hline & ALMOST NEVER & 16 & 13.3 & 13.4 & 47.1 \\
\hline & SOMETIMES & 41 & 34.2 & 34.5 & 81.5 \\
\hline & FAIRLY OFTEN & 12 & 10.0 & 10.1 & 91.6 \\
\hline & VERY OFTEN & 10 & 8.3 & 8.4 & 100.0 \\
\hline & Total & 119 & 99.2 & 100.0 & \\
\hline Missing & System & 1 & .8 & & \\
\hline \multicolumn{2}{|l|}{ Total } & 120 & 100.0 & & \\
\hline
\end{tabular}

Table-16: Mean score of Numerical rating scale (NRS)

\begin{tabular}{|l|l|l|}
\hline \multicolumn{2}{|c|}{ Statistics } \\
\hline NRS \\
\hline \multirow{2}{*}{$\mathrm{N}$} & Valid & 119 \\
\cline { 2 - 3 } & Missing & 1 \\
\hline Mean & 4.57 \\
\hline Std. Deviation & 2.234 \\
\hline Minimum & 0 \\
\hline Maximum & 10 \\
\hline
\end{tabular}

Table-17: Wilcoxon signed rank test showing prevalence of Myofascial trigger point in UT, LS and SCM Rank

\begin{tabular}{|c|c|c|c|c|c|}
\hline & & & $\mathbf{N}$ & Mean Rank & Sum of Ranks \\
\hline exams - semester & \multicolumn{2}{|c|}{ Negative Ranks } & $15^{\mathrm{a}}$ & 44.2 & 663 \\
\hline (right Trapezius) & \multicolumn{2}{|c|}{ Positive Ranks } & $66^{\mathrm{b}}$ & 40.27 & 2658 \\
\hline & \multicolumn{2}{|l|}{ Ties } & $38^{\mathrm{c}}$ & & \\
\hline & \multicolumn{2}{|l|}{ Total } & 119 & & \\
\hline exams - semester & \multicolumn{2}{|c|}{ Negative Ranks } & $18^{\mathrm{d}}$ & 40.19 & 723.5 \\
\hline (left Trapezius) & \multicolumn{2}{|c|}{ Positive Ranks } & $66^{\mathrm{e}}$ & 43.13 & 2846.5 \\
\hline & \multicolumn{2}{|c|}{ Ties } & $35^{\mathrm{f}}$ & & \\
\hline & \multicolumn{2}{|l|}{ Total } & 119 & & \\
\hline exams - semester & \multicolumn{2}{|c|}{ Negative Ranks } & $10^{\mathrm{g}}$ & 27.4 & 274 \\
\hline (right SCM) & \multicolumn{2}{|c|}{ Positive Ranks } & $33^{\mathrm{h}}$ & 20.36 & 672 \\
\hline & \multicolumn{2}{|l|}{ Ties } & $76^{i}$ & & \\
\hline & \multicolumn{2}{|l|}{ Total } & 119 & & \\
\hline exams - semester & \multicolumn{2}{|c|}{ Negative Ranks } & $9^{j}$ & 22.28 & 200.5 \\
\hline (left SCM) & \multicolumn{2}{|c|}{ Positive Ranks } & $30^{\mathrm{k}}$ & 19.32 & 579.5 \\
\hline & \multicolumn{2}{|c|}{ Ties } & $80^{1}$ & & \\
\hline & \multicolumn{2}{|l|}{ Total } & 119 & & \\
\hline exams - semester & \multicolumn{2}{|c|}{ Negative Ranks } & $14^{\mathrm{m}}$ & 24.14 & 338 \\
\hline (right levetor scapulae) & \multicolumn{2}{|c|}{ Positive Ranks } & $49^{n}$ & 34.24 & 1678 \\
\hline & \multicolumn{2}{|l|}{ Ties } & $56^{\circ}$ & & \\
\hline & \multicolumn{2}{|l|}{ Total } & 119 & & \\
\hline exams - semester & \multicolumn{2}{|c|}{ Negative Ranks } & $10^{\mathrm{p}}$ & 25.9 & 259 \\
\hline (left levetor scapulae) & \multicolumn{2}{|c|}{ Positive Ranks } & $65^{q}$ & 39.86 & 2591 \\
\hline & \multicolumn{2}{|c|}{ Ties } & $44^{\mathrm{r}}$ & & \\
\hline & \multicolumn{2}{|l|}{ Total } & 119 & & \\
\hline \multicolumn{4}{|c|}{ j. exams $<$ semester } & & \\
\hline b. exams > semester & & \multicolumn{2}{|c|}{ k. exams > semester } & & \\
\hline c. exams $=$ semester & & \multicolumn{2}{|c|}{ 1. exams $=$ semester } & & \\
\hline d. exams < semester & & \multicolumn{2}{|c|}{ m. exams < semester } & & \\
\hline e. exams > semester & & \multicolumn{2}{|c|}{ n. exams > semester } & & \\
\hline f. exams = semester & & o. exam & emester & & \\
\hline g. exams $<$ semester & & p. exam & emester & & \\
\hline h. exams > semester & & q. exam & mester & & \\
\hline i. exams $=$ semester & & r. exam & mester & & \\
\hline
\end{tabular}

\begin{tabular}{|l|l|l|l|l|l|l|}
\hline \multicolumn{9}{|c|}{ Test Statistics $^{\mathbf{b}}$} \\
\hline & $\begin{array}{l}\text { exams } \\
\text { semester }\end{array}$ & $\begin{array}{l}\text { exams } \\
\text { semester }\end{array}$ & $\begin{array}{l}\text { exams } \\
\text { semester }\end{array}$ & $\begin{array}{l}\text { exams } \\
\text { semester }\end{array}$ & $\begin{array}{l}\text { exams } \\
\text { semester }\end{array}$ & $\begin{array}{l}\text { exams } \\
\text { semester }\end{array}$ \\
\hline $\mathrm{Z}$ & $-4.832^{\mathrm{a}}$ & $-4.871^{\mathrm{a}}$ & $-2.501^{\mathrm{a}}$ & $-2.728^{\mathrm{a}}$ & $-4.675^{\mathrm{a}}$ & $-6.269^{\mathrm{a}}$ \\
\hline Asymp. Sig. (2-tailed) & .000 & .000 & .012 & .006 & .000 & .000 \\
\hline a. Based on negative ranks. \\
\hline
\end{tabular}




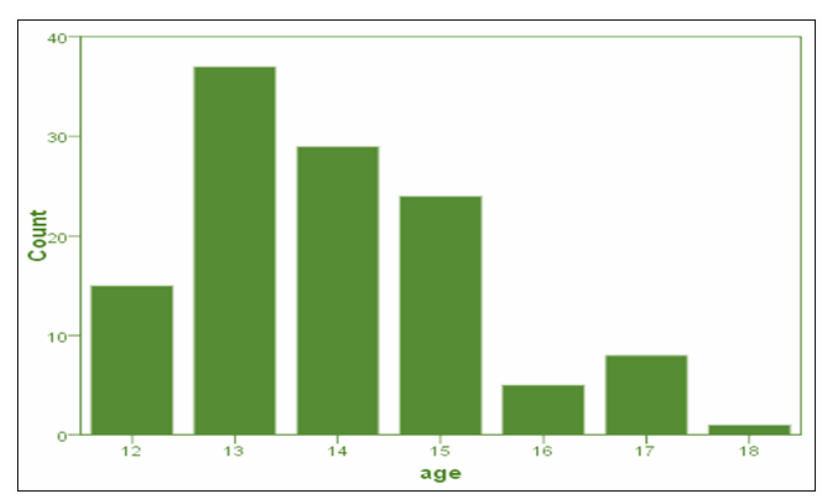

Fig-1: Mean age of participants

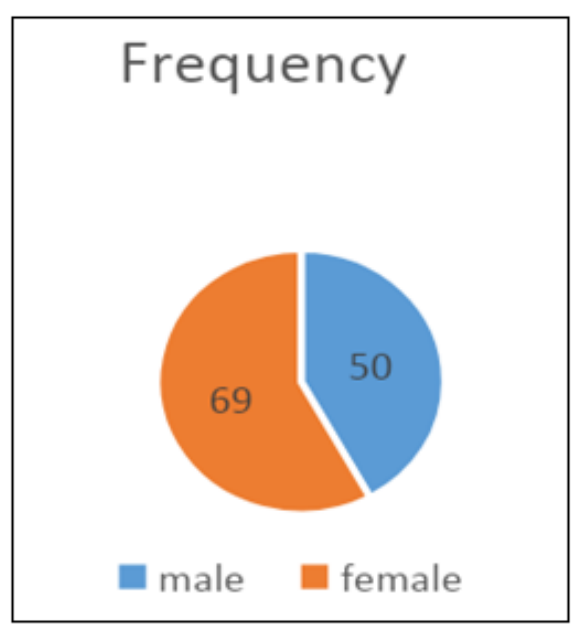

Fig-2: Frequency of gender

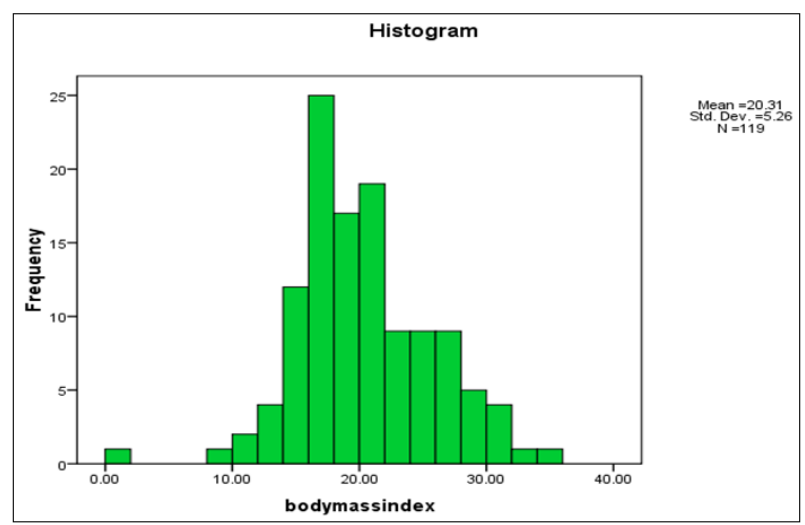

Fig-3: Mean of body mass index (BMI)

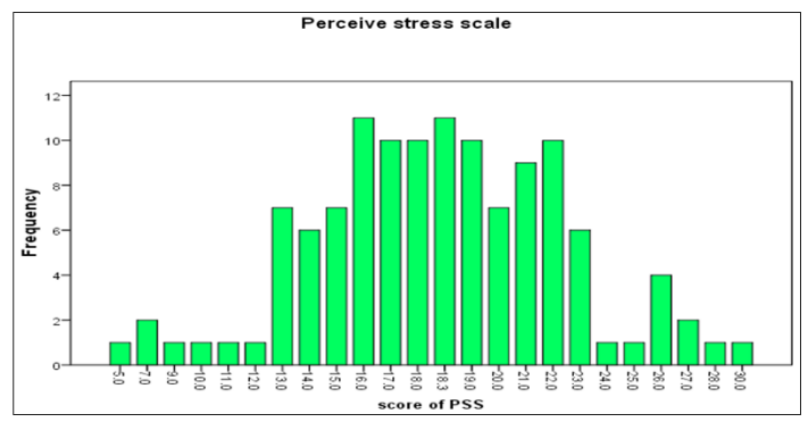

Fig-4: Mean of PSS Scores

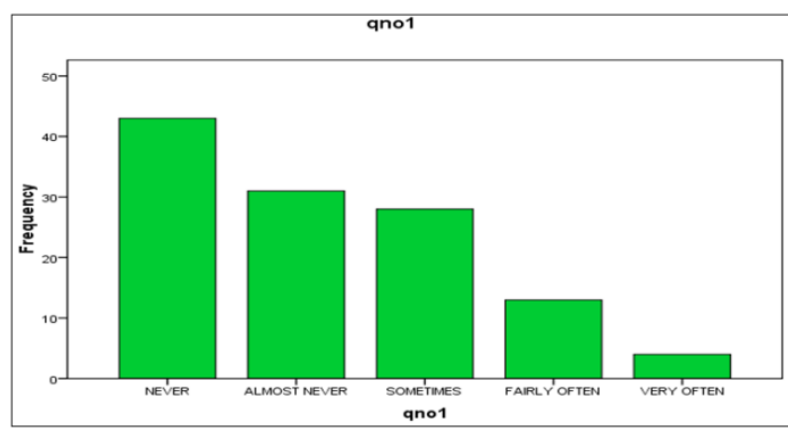

Fig-5: How much participant had been upset

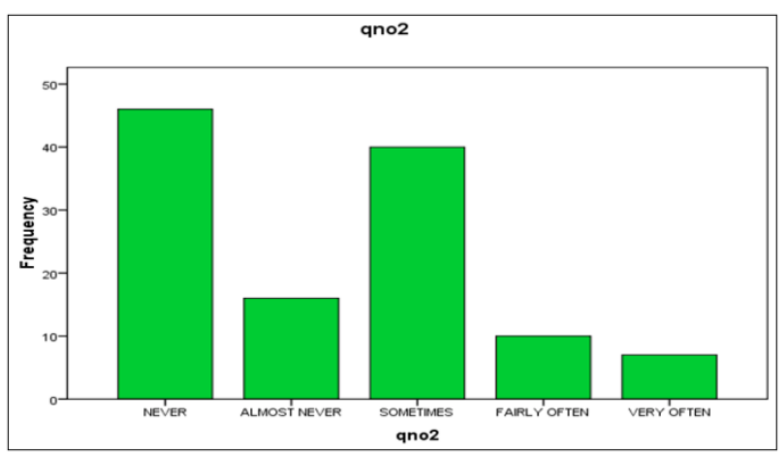

Fig-6: Participant feeling about control of their emotions

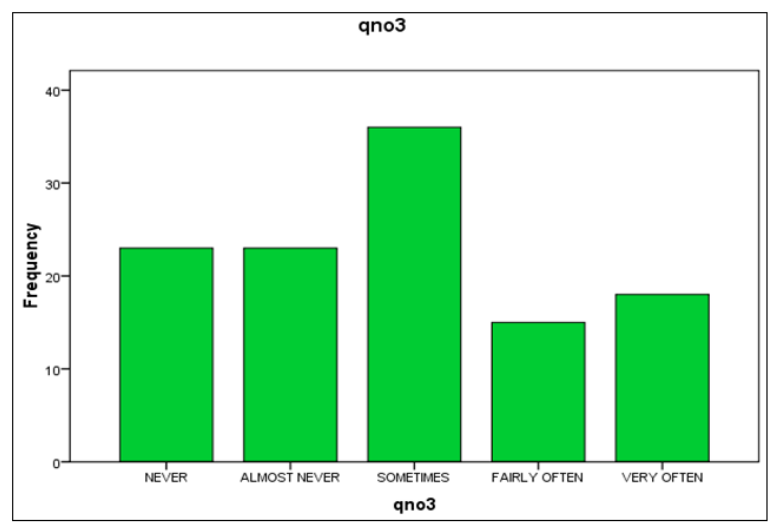

Fig-7: Participant feeling about nervousness and stress

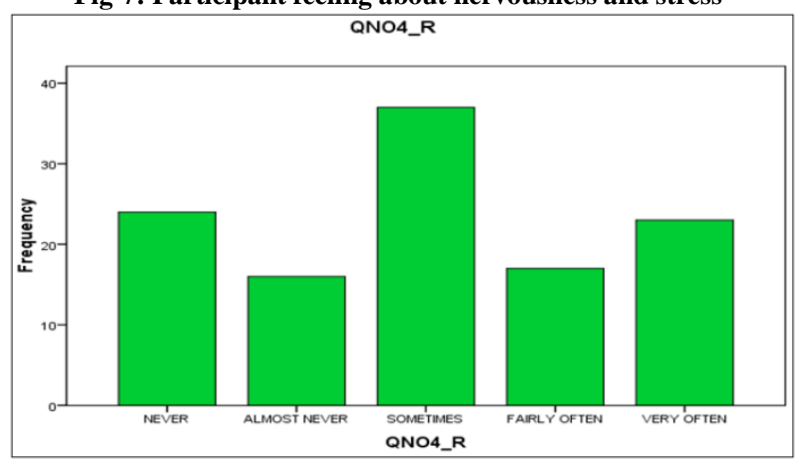

Fig-8: Participants feeling about their confidents 


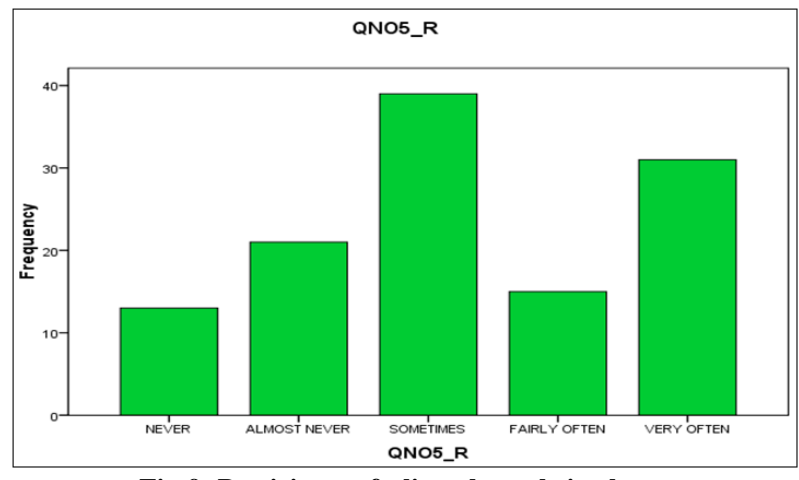

Fig-9: Participants feeling about their plans

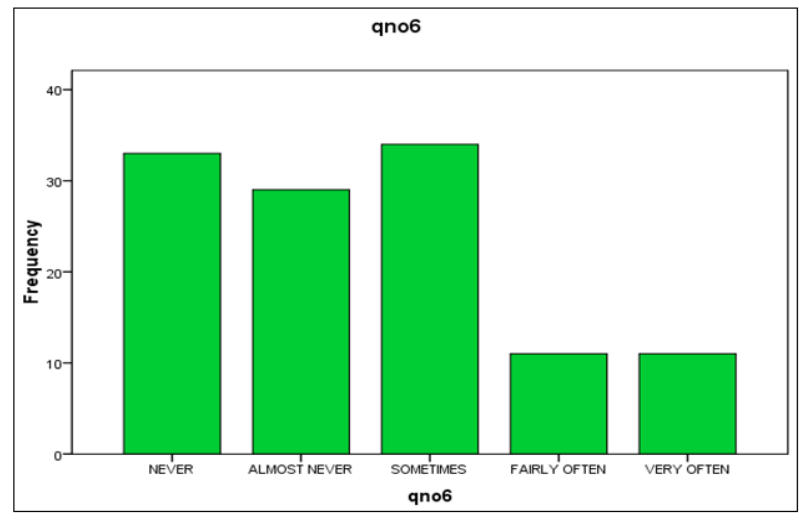

Fig-10: Participant feeling about their coping ability

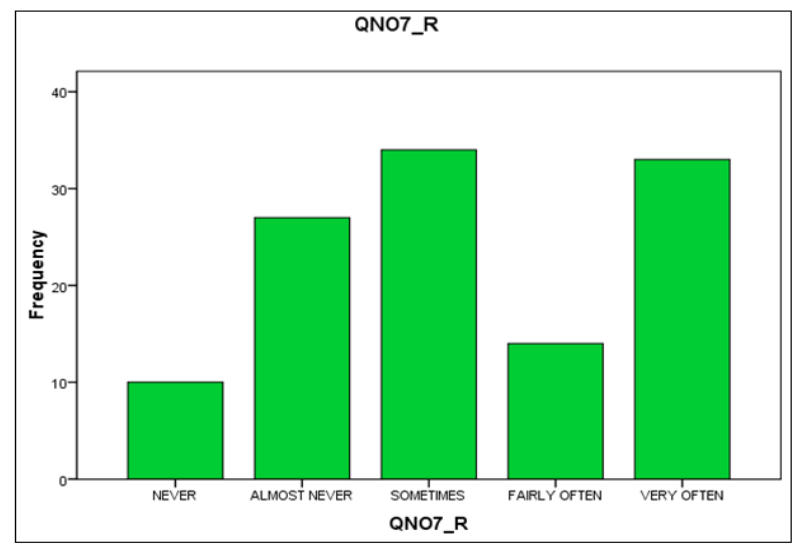

Fig-11: Participants feeling about their control of life

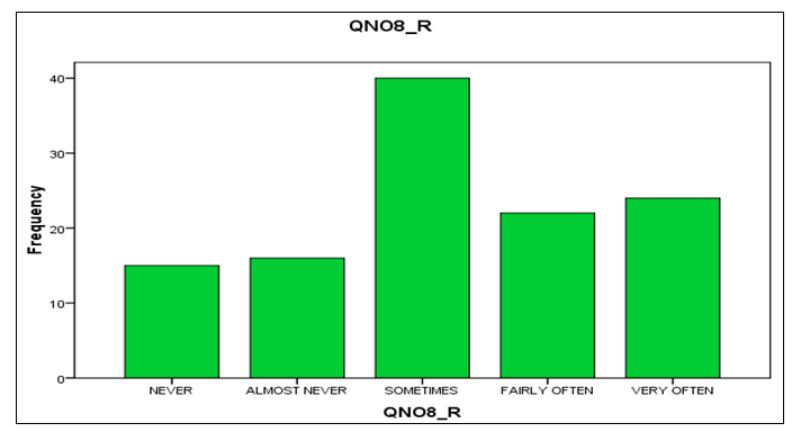

Fig-12: Participant feeling about their confident

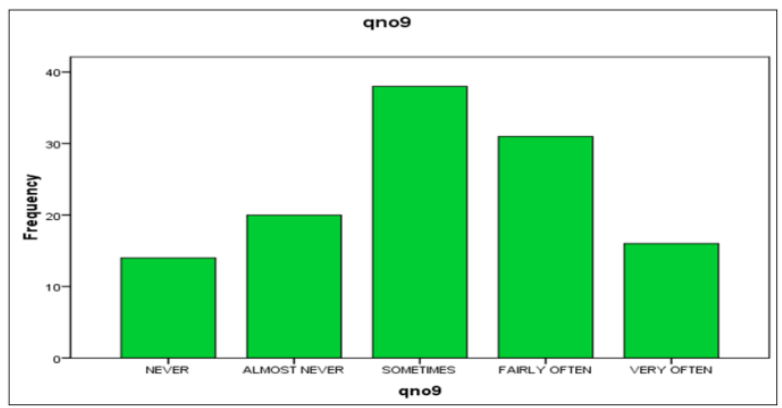

Fig-13: Participants feeling about anger

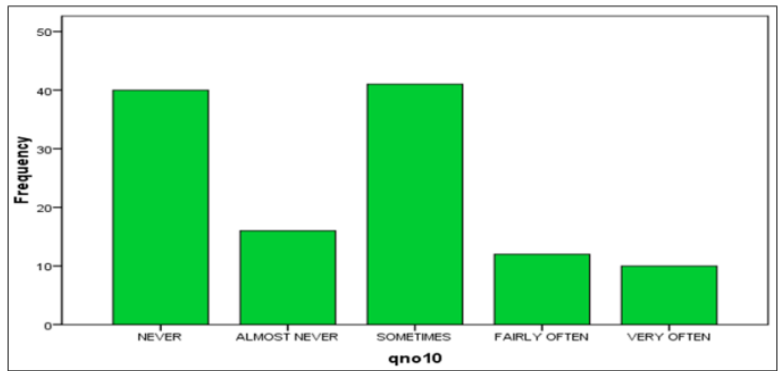

Fig-14: Participants feeling about their difficulties

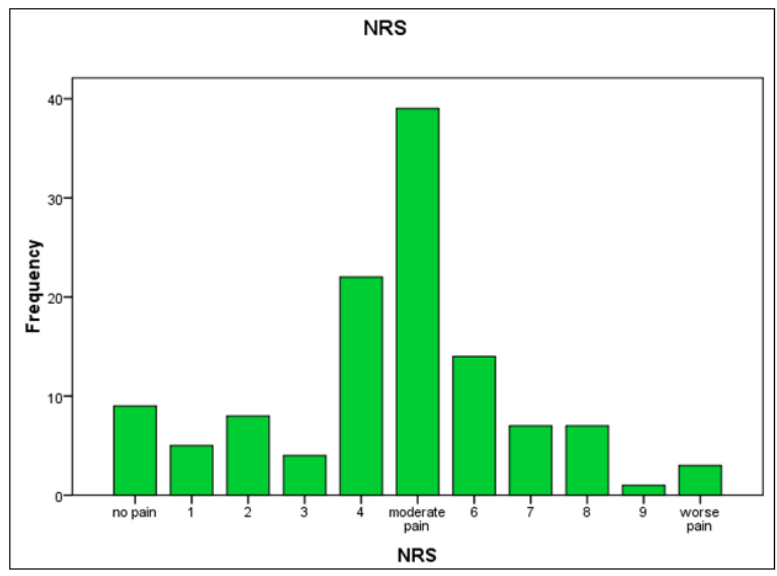

Fig-15: Mean score of Numerical rating scale (NRS)

\section{CONCLUSION}

The finding of this study revealed a greater prevalence of MTrPs in neck musculature and a moderate intensity of pain reported on NRS score. It is still unclear that pain intensity increases with exam or not. Also, there is lacking in regard to the establishment of difference between exam stresses or prolong mental demand during exams for the preparation of exams. Further studies should be needed to fulfill this requirement. The author suggests that preventive measure should be considered for students to whether decrease mental stress or mental demand in exams period.

\section{REFERENCES}

1. Myofascial Trigger Point Therapy - What is it? (n.d.). Retrieved from https://namtpt.wildapricot.org/MTPT_What_is_it/

2. Elsevier. (2013, May 17). Myofascial Trigger Points - 1st Edition. Retrieved from 
https://www.elsevier.com/books/myofascialtrigger-points/irnich/978-0-7020-4312-3

3. Mechanisms of Myofascial Pain. (2014, August 18). Retrieved from https://www.hindawi.com/journals/isrn/2014/5239 $24 /$.

4. A New Look at Trigger Point Injections. (n.d.). Retrieved from https://www.ncbi.nlm.nih.gov/pmc/articles/PMC3 182370/

5. Trigger Points. (n.d.). Retrieved from https://www.physio-pedia.com/Trigger_Points

6. Alvarez DJ and Rockwell PG. (n.d.). Trigger points: diagnosis and management. - PubMed NCBI. Retrieved from https://www.ncbi.nlm.nih.gov/pubmed/11871683

7. Myofascial trigger point. (2005, March 20). Retrieved from https://en.wikipedia.org/wiki/Myofascial_trigger_ point

8. CZ, H. (n.d.). Pathophysiology of myofascial trigger point. - PubMed - NCBI. Retrieved from https://www.ncbi.nlm.nih.gov/pubmed/9064014

9. Redirecting... (2017, May 21). Retrieved from http://fibronewsdaily.com/2017/05/21/triggerpoints-diagnosis-and-management/

10. Clinical features of myofascial trigger points. (n.d.). Retrieved from http://www.paineducation.com/clinical-features-of-myofascialtrigger-points.html

11. APPENDIX MYOFASCIAL PAIN SYNDROMES DUE TO TRIGGER POINTS Pain and Disability - NCBI Bookshelf. (n.d.). Retrieved from https://www.ncbi.nlm.nih.gov/books/NBK219241/

12. Retrieved from https://www.myalgia.com/BURCKHARDT\%20R EVIEW.htm

13. Simons, D. G., Travell, J. G., \& Simons, L. S. (1999). Travell \& Simons' Myofascial Pain and Dysfunction: Upper half of body. Philadelphia, PA: Lippincott Williams \& Wilkins.

14. Massage Techniques. (n.d.). Retrieved from https://www.realbodywork.com/articles/massagetechniques/

15. Simons, D. G., Travell, J. G., \& Simons, L. S. (1999). Travell \& Simons' Myofascial Pain and Dysfunction: Upper half of body. Philadelphia, PA: Lippincott Williams \& Wilkins.

16. Cagnie, B., Dewitte, V., Coppieters, I., Van Oosterwijck, J., Cools, A., \& Danneels, L. (2013). Effect of Ischemic Compression on Trigger Points in the Neck and Shoulder Muscles in Office Workers: A Cohort Study. Journal of Manipulative and Physiological Therapeutics, 36(8), 482-489.

17. Catherine Burt Driver, MD. (n.d.). Trigger Point Injection Side Effects \& Medications. Retrieved from https://www.medicinenet.com/trigger_point_inject ion/article.htm\#trigger_point_injection_tpi_facts

18. Trigger Point Acupuncture Practitioner - Absolute Qi - Somerset NJ. (n.d.). Retrieved from http://triggerpointacupuncture.com

19. Kalichman, L., Bulanov, N., \& Friedman, A. (2017). Effect of exams period on prevalence of Myofascial Trigger points and head posture in undergraduate students: Repeated measurements study. Journal of Bodywork and Movement Therapies, 21(1), 11-18.

20. Miles, D. (2016). Re: "Dry Needling Alters Trigger Points in the Upper Trapezius Muscle and Reduces Pain in Subjects with Chronic Myofascial Pain". PM\&R, 8(12), 1225-1226.

21. Muñoz-Muñoz, S., Muñoz-García, M. T., Alburquerque-Sendín, F., Arroyo-Morales, M., \& Fernández-de-las-Peñas, C. (2012). Myofascial Trigger Points, Pain, Disability, and Sleep Quality in Individuals with Mechanical Neck Pain. Journal of Manipulative and Physiological Therapeutics, 35(8), 608-613.

22. Simons, D. G., Hong, C., \& Simons, L. S. (2002). Endplate Potentials Are Common to Midfiber Myofacial Trigger Points. American Journal of Physical Medicine \& Rehabilitation, 81(3), 212222.

23. Srbely, J. Z., \& Dickey, J. P. (2007). Randomized controlled study of the antinociceptive effect of ultrasound on trigger point sensitivity: novel applications in myofascial therapy? Clinical Rehabilitation, 21(5), 411-417.

24. Jaeger, B., \& Reeves, J. L. (1986). Quantification of changes in myofascial trigger point sensitivity with the pressure algometer following passive stretch. Pain, 27(2), 203-210.

25. Lee, M., Kim, M., Oh, S., Choi, Y., Lee, D., Lee, S. H., \& Yoon, B. (2017). A selfdetermination theory-based self-myofascial release program in older adults with myofascial trigger points in the neck and back: A pilot study. Physiotherapy Theory and Practice, 33(9), 681-694.

26. Shah, J. P., Danoff, J. V., Desai, M. J., Parikh, S., Nakamura, L. Y., Phillips, T. M., \& Gerber, L. H. (2008). Biochemicals Associated with Pain and Inflammation are Elevated in Sites Near to and Remote From Active Myofascial Trigger Points. Archives of Physical Medicine and Rehabilitation, 89(1), 16-23.

27. Fernández-de-las-Peñas, C., Alonso-Blanco, C., \& Miangolarra, J. (2007). Myofascial trigger points in subjects presenting with mechanical neck pain: A blinded, controlled study. Manual Therapy, 12(1), 29-33.

28. Treatment of myofascial trigger-points with ultrasound combined wiht massage and exercise - a randomized controlled trial. (1999). Complementary Therapies in Medicine, 7(4), 259. 
29. Moraska, A. F., $\quad$ Stenerson, L., $\quad$ Butryn, N., Krutsch, J. P., Schmiege, S. J., \& Mann, J. D. (2015). Myofascial Trigger Point-focused Head and Neck Massage for Recurrent Tension-type Headache. The Clinical Journal of Pain,31(2), 159-168.

30. Fernández-de-las-Peñas, C., FernándezMayoralas, D. M., Ortega-Santiago, R., AmbiteQuesada, S., Palacios-Ceña, D., \& Pareja, J. A. (2011). Referred pain from myofascial trigger points in head and neck-shoulder muscles reproduces head pain features in children with chronic tension type headache. The Journal of Headache and Pain, 12(1), 35-43.

31. Hashemirad, F., Karimi, N., \& Keshavarz, R. (2016). The effect of Kinesio taping technique on trigger points of the piriformis muscle. Journal of Bodywork and Movement Therapies, 20(4), 807814.

32. Gerber, L. H., $\quad$ Shah, J., $\quad$ Rosenberger, W., Armstrong, K., Turo, D., Otto, P., ... Sikdar, S. (2015). Dry Needling Alters Trigger Points in the Upper Trapezius Muscle and Reduces Pain in Subjects With Chronic Myofascial Pain. $P M \& R, 7(7), 711-718$.

33. Abbaszadeh-Amirdehi, M., Ansari, N. N., Naghdi, S., Olyaei, G., \& Nourbakhsh, M. R. (2017). Neurophysiological and clinical effects of dry needling in patients with upper trapezius myofascial trigger points. Journal of Bodywork and Movement Therapies, 21(1), 48-52.

34. Cagnie, B., Castelein, B., Pollie, F., Steelant, L., Verhoeyen, H., \& Cools, A. (2015). Evidence for the Use of Ischemic Compression and Dry Needling in the Management of Trigger Points of the Upper Trapezius in Patients with Neck Pain. American Journal of Physical Medicine \& Rehabilitation, 94(7), 573-583.

35. Moraska, A. F., Schmiege, S. J., Mann, J. D., Butryn, N., \& Krutsch, J. P. (2017). Responsiveness of Myofascial Trigger Points to Single and Multiple Trigger Point Release Massages. American Journal of Physical Medicine \& Rehabilitation, 96(9), 639-645.

36. Amjad, F., Shahid, H., Batool, S., Ahmad, A., \& Ahmed, I. (2016). A Comparison On Efficacy Of Transcutaneous Electrical Nerve Stimulation And Therapeutic Ultrasound In Treatment Of Myofascial Trigger Points. Khyber Medical University Journal,8(1). Retrieved from https://www.kmuj.kmu.edu.pk/article/view/15769

37. Segura-Ortí, E., Prades-Vergara, S., ManzanedaPiña, L., Valero-Martínez, R., \& Polo-Traverso, J. (2016). Trigger Point Dry Needling versus Straincounterstrain Technique for Upper Trapezius Myofascial Trigger Points: A Randomised
Controlled Trial. Acupuncture in Medicine, 34(3), 171-177.

38. Llamas-Ramos, R., Pecos-Martín, D., GallegoIzquierdo, T., Llamas-Ramos, I., PlazaManzano, G., Ortega-Santiago, R.,... Fernándezde-las-Peñas, C. (2014). Comparison of the ShortTerm Outcomes Between Trigger Point Dry Needling and Trigger Point Manual Therapy for the Management of Chronic Mechanical Neck Pain: A Randomized Clinical Trial. Journal of Orthopaedic \& Sports Physical Therapy, 44(11), 852-861.

39. Boyles, R., Fowler, R., Ramsey, D., \& Burrows, E. (2015). Effectiveness of trigger point dry needling for multiple body regions: a systematic review. Journal of Manual \& Manipulative Therapy, 23(5), 276-293.

40. Morikawa, Y., Takamoto, K., Nishimaru, H., Taguchi, T., Urakawa, S., Sakai, S., ... Nishijo, H. (2017). Compression at Myofascial Trigger Point on Chronic Neck Pain Provides Pain Relief through the Prefrontal Cortex and Autonomic Nervous System: A Pilot Study. Frontiers in Neuroscience, 11 .

41. Mejuto-Vázquez, M. J., Salom-Moreno, J., Ortega-Santiago, R., Truyols-Domínguez, S., \& Fernández-de-las-Peñas, C. (2014). Short-Term Changes in Neck Pain, Widespread Pressure Pain Sensitivity, and Cervical Range of Motion After the Application of Trigger Point Dry Needling in Patients With Acute Mechanical Neck Pain: A Randomized Clinical Trial. Journal of Orthopaedic \& Sports Physical Therapy,44(4), 252-260.

42. McEvoy, J. (2013). Trigger point dry needling. Trigger Point Dry Needling, 39-58.

43. Ilbuldu, E., Cakmak, A., Disci, R., \& Aydin, R. (2004). Comparison of Laser, Dry Needling, and Placebo Laser Treatments in Myofascial Pain Syndrome. Photomedicine and Laser Surgery, 22(4), 306-311.

44. Dry Needling For Myofascial Trigger Point Pain: A Clinical Commentary. (n.d.). international journal of sports physiotherapy.

45. Lucas, N., Macaskill, P., Irwig, L., Moran, R., \& Bogduk, N. (2009). Reliability of Physical Examination for Diagnosis of Myofascial Trigger Points. The Clinical Journal of Pain, 25(1), 80-89.

46. Phan, N., Blome, C., Fritz, F., Gerss, J., Reich, A., Ebata, T., ... Ständer, S. (2012). Assessment of Pruritus Intensity: Prospective Study on Validity and Reliability of the Visual Analogue Scale, Numerical Rating Scale and Verbal Rating Scale in 471 Patients with Chronic Pruritus. Acta Dermato Venereologica, 92(5), 502-507. 